\title{
In vitro Antimicrobial Investigations of Newly Synthesized Transitional Bivalent Metal Complexes Derived from 8-Hydroxyquinoline
}

\author{
Sahoo Jyotirmaya ${ }^{1 *}$, Sarangi Priyambada Kshiroda Nandini², Paidesetty Sudhir Kumar ${ }^{3}$ \\ ${ }^{1}$ Department of Pharmaceutics, Sri Jayadev College of Pharmaceutical Sciences, Bhubaneswar, Orissa, INDIA \\ ${ }^{2}$ Departmentof Pharmaceutical Chemistry, Sri Jayadev College of Pharmaceutical Sciences, Bhubaneswar, Orissa, INDIA. \\ 'Department of Pharmaceutical Chemistry, School of Pharmaceutical Sciences, Siksha 'O' Anusandhan University, Bhubaneswar, \\ Orissa, INDIA.
}

\begin{abstract}
Introduction: Novel $\mathrm{Cu}(\mathrm{II}), \mathrm{Co}(\mathrm{II})$ and $\mathrm{Ni}(\mathrm{II})$ complexes of 8-hydroxyquinolineazo analogues are synthesized from 5-((3-nitrophenyl)diazenyl) quinolin-8-ol (4a) and 5-((4-bromo-3methylphenyl) diazenyl) quinolin-8-ol (4b). Methods: The structural environment and elemental composition of the synthesized metal complexes are confirmed by $F T / I R,{ }^{1} \mathrm{H}$ NMR and CHNS/O elemental analyzer. The $\lambda_{\max }$ and molecular mass are determined with the help of UV-visible and LC-MS spectrometer. Results: The magnetic susceptibility study suggested that the synthesized complexes are proposed with tetrahedral geometry. Among the six complexes, the bis bis 8, 8' [5-((3-nitrophenyl) diazenyl) quinolinium] copper $\left(\mathbf{4 a L i g}_{2} \mathrm{Cu}\right)$ and bis $8, \mathbf{8}^{\prime}$ [5-((4-bromo-3-methylphenyl) diazenyl) quinolinium] copper $\left(\mathbf{4} \mathbf{b L i g}_{2} \mathbf{C u}\right)$ showed significant antimicrobial activity. Conclusion: It was found that the metal complexes showed enhanced antimicrobial activity in comparison to their corresponding ligands.
\end{abstract}

Key words: Spectroscopic, Magnetic susceptibility, Antimicrobial, 8-Hydroxy quiniline, Antibiogram.

\section{INTRODUCTION}

Antimicrobial resistance is a global problem which challenges our ability to combat common infectious diseases. This occurs naturally over time through genetic changes or may results due to the vitality of the germs those are not killed with their cease less growth. According to the opinion of World health leaders, antibiotic resistant microorganisms are the nightmare bacteria that cause a notable disaster to a huge population in the world. According to the current outcome, 2 million people are suffering from serious infections and 23,000 people are dying due to these superbugs in the United States every year. Also the report of antibiotic resistance threats in the United states 2013 reveals that Candida causes serious illness among hospital patients is show- ing an unambiguous increase in multidrug registance. ${ }^{1}$ According to the global report on surveillance of World Health Organisation in 2014, the antibiotic resistance due to Escherchia coli in urinary tract infections and the resistance offered by Pseudomonas aeruginosa, Klebsiella pneumonia etc. in case of pneumonia is highest in the southeast, east central and south Atlantic states (antimicrobial resistance: global report on surveillance, WHO 2014). To forestall the deadly infections due to the antibiotic resistant superbugs, the WHO recommended instructions are preventing infections and preventing the spread of resistance, tracking resistant bacteria, improving the use of today's antibiotics and promoting the development of new antibiotics and develop-
Submission Date: 07-12-2016; Revision Date: 03-01-2017; Accepted Date: 15-02-2017

DOI: 10.5530/ijper.51.3.76 Correspondence: Jyotirmaya Sahoo, Assistant Professor, Department of Pharmaceutics,Sri Jayadev College of Pharmaceutical Sciences, Bhubaneswar 752101, orissa, INDIA. Phone: +919861433157 E-mail: jjyotisahoo@rediffmail.com 
ing new diagnostic tests for resistant bacteria. Though many investigations are going on to combat the multidrug resistant microorganisms since past few years, still a lot many inventions are required for development of newer and potent molecules for enhancement of the Antibiotic treatment options. 8-Hydroxyquinoline $(8-\mathrm{HQ})$ the quinoline derivative can obtain from plants as well as synthetically in the laboratory. 8-HQ possesses potent coordinating ability and good metal recognition properties. ${ }^{2}$ In addition to these they have good chelating ability toward a great number of metal cations. ${ }^{3}$ Among seven isomeric mono hydroxyquinolines, only 8-HQ is capable of forming complexes with divalent metal ions through chelation. ${ }^{4}$ The heterocyclic nitrogen compounds bearing 8-HQ nucleus have potential biological activities as well as good complexing agents. ${ }^{5,6} 8$-hydroxyquinoline and its derivatives are well known bidentate ligands. It has been used as a fungicide in agriculture and a preservative in the textile, wood, and paper industries. ${ }^{7}$ 8-hydroxyquinoline derivatives have versatile therapeutic activities such as antiseptic, ${ }^{8}$ antiviral, ${ }^{9}$ antimicrobial, ${ }^{10}$ antitumor, ${ }^{11}$ antiinflammatory, ${ }^{12}$ anti-asthmatic and analgesic, ${ }^{13}$ antioxidant, ${ }^{5}$ anti-neurodegenerative \& anti-diabetic ${ }^{14}$ and anti-HIV. The organic compounds coordinated with metals cause drastic change in the biological property of the ligand..$^{15}$ The transition metal complexes have shown significant biological actions including antibacterial, antifungal and anticancer activities. ${ }^{5}$ Metal ions can induce toxicity but metal imbalance can cause many diseases. In this regards, 8-HQ which is a potent chelator may restore metal balance and can be useful for the treatment of metal-related diseases. Moreover the azo compounds are known to be involved in numbers of biological functions, such as inhibition of nucleic acids, protein synthesis, nitrogen fixation and carcinogenesis. ${ }^{16}$ Azo derivatives and their metal complexes are also very important pigments for synthetic leather and vinyl polymers. ${ }^{17}$ They are the potent pharmaceuticals agents which having versatile therapeutic activities like antiseptic, ${ }^{18}$ antimicrobial ${ }^{19-22}$ antidiabetic, ${ }^{23}$ antineoplastic, ${ }^{24}$ antitumor ${ }^{25}$ activities, DNA, RNA, and protein synthesis, nitrogen fixation, and carcinogenesis. ${ }^{26}$ The azo compounds based on 8-hydroxyquinoline play a central role as chelating agents for large number of metal ions, as they can form a stable six-member ring after complexation with the metal ion. The intra-molecular and intermolecular association through hydrogen bonding could be assumed to exist in 5-(substituted phenylazo)8-hydroxyquinoline derivatives. ${ }^{27}$ In the continuation of our earlier reported work, ${ }^{5}$ the present investigation is mainly focused on the synthesis of a wide range of metal complexes by co-ordination of transitional metal chlorides with 8-hydroxyquinolineazo analogues and to investigate their biological properties.

\section{EXPERIMENTAL SECTION}

\section{Chemicals and Analysis}

All the chemicals used in the present studies were of synthetic grade and sourced from Merck specialties Ltd. (Mumbai, India) and used without purification. The Elemental analysis of the novel synthesized molecules for $\mathrm{C}, \mathrm{H}, \mathrm{N}$ and $\mathrm{S}$ were performed using Perkin Elmer model $2400 \mathrm{CHNS} / \mathrm{O}$ analyzer. Further the prepared products were analyzed by FT/IR (JASCO FT/IR 4100 Spectrophotometer) using $\mathrm{KBr}$ pellets. ShimadzuMass spectrophotometer with column $\mathrm{C}_{6}(150 \mathrm{~mm} \times$ $4.6 \mathrm{~mm}), 5 \mu \mathrm{m}$ particle size was used to determine the molecular mass. The ${ }^{1} \mathrm{H}$ NMR spectra were recorded on a Bruker ${ }^{1} \mathrm{H}$ NMR $400 \mathrm{MHZ}$ using DMSO- $d 6$ as a solvent with tetramethylsilane as an internal standard and the chemical shifts were reported on $\delta \mathrm{ppm}$. The UVVis spectrosopy (Jasco V-630 Spectrophotometer) is used to study $\lambda_{\text {max }}$ of the synthesized molecules. The melting points were determined by open capillary method (Elico) and are uncorrected. Faraday balance technique was employed to measure the magnetic susceptibility of the metal complexes. The in vitro antimicrobial activities against different bacterial and fungal pathogens were performed by agar well diffusion method, sourced from CSIR IMTECH, India, Chandigarh.

\section{Synthesis of 5-((3-nitrophenyl) diazenyl) quinolin- 8-ol (4a) and 5-((4-bromo-3-methylphenyl) diazenyl) quinolin-8-ol (4b)}

The synthesis of the compounds 5-((3-nitrophenyl) diazenyl) quinolin-8-ol (4a) and 5-((4-bromo-3-methylphenyl) diazenyl) quinolin-8-ol (4b) azo analogues was carried out as earlier reported. ${ }^{5}$

\section{Synthesis of metal complexes of azoquinoline analogues (4a Lig $_{2} \mathrm{M}$ and $4 \mathrm{~b}$ Lig $\left._{2} \mathrm{M}\right)^{17,21}$}

A mixture of $25 \mathrm{~mL}$ was prepared with appropriate transitional metal ions $\mathrm{Cu}(\mathrm{II}), \mathrm{Co}(\mathrm{II})$ and $\mathrm{Ni}(\mathrm{II})$ of $10 \mathrm{mmol}$ in ethanol and water 1:1. The above mixture was added to the solution of respective azo compounds $4 a$ and $4 b$ $(0.40 \mathrm{~g}, 10 \mathrm{mM})$ in ethanol and water in equal ratio to obtain $50 \mathrm{~mL}$. The resulting solution was refluxed for $30 \mathrm{~min}$ at a controlled temperature not more than $78^{\circ} \mathrm{C}$. The obtained precipitates were filtered and washed with equal proportion of ethanol-water and finally re-crystallized from diethyl ether. The progress of reaction was 
monitored by TLC with solvent system of ethyl acetae and cyclohexane at 1:5.

5-((3-nitrophenyl) diazenyl) quinolin-8-ol (4a): Gray colour; Yield $90 \%$; $\mathrm{R}_{\mathrm{p}}$; 0.7, $\mathrm{mp}\left({ }^{\circ} \mathrm{C}\right) ; 278-280$; UV-vis $\left(\lambda_{\max }, \mathrm{nm}, \mathrm{DMSO}\right): 463$; IR $\left(\mathrm{KBr}, \gamma, \mathrm{cm}^{-1}\right): 3432(\mathrm{O}-\mathrm{H}$ str.), 1608 (C=C str.), 1586, (C=N str. Quinolinyl), 1506 $(-\mathrm{N}=\mathrm{N}-), 1338\left(\mathrm{NO}_{2}\right.$ str.); ${ }^{1} \mathrm{H}$ NMR (DMSO- $d_{6}, \delta \mathrm{ppm}$, 300 MHZ): 9.67 (s, 1H, 8-OH), 8.10-8.66 (4H, ArylH), 9.11 (d, Quinolinyl H-2), 7.78 (d, Quinolinyl H-3), 8.33 (d, Quinolinyl H-4), 7.87 (d, Quinolinyl H-6), 7.32 (d, Quinolinyl H-7); LC-MS (\% area); 93; $\mathrm{m} / \mathrm{z} ; 295.17$ $(\mathrm{M}+1)$; Analysis for $\mathrm{C}_{15} \mathrm{H}_{10} \mathrm{~N}_{4} \mathrm{O}_{3}$ : Calcd \% C, 61.22; $\mathrm{H}$, 3.43; N, 19.04; Found \%: C, 61.25; H, 3.41; N, 19.07 .

5-((4-bromo-3-methylphenyl) diazenyl) quinolin-8-ol (4b): Dark red colour; Yield $97 \%$; $\mathrm{R}_{\mathrm{p}} ; 0.8, \mathrm{mp}\left({ }^{\circ} \mathrm{C}\right) ; 260$ 263; UV-vis $\left(\lambda_{\max }, \mathrm{nm}, \mathrm{DMSO}\right): 404$; IR $\left(\mathrm{KBr}, \gamma, \mathrm{cm}^{-1}\right)$ : 3290 (O-H str), $2922\left(\mathrm{CH}_{2}\right.$ str $\left.\mathrm{CH}_{3}\right), 1578(\mathrm{C}=\mathrm{N}$ str. Quinolinyl), 1503 (-N=N-), 621 (C-Br), 885 (1, 2, 4 trisubst. Ar-H); ${ }^{1} \mathrm{H}$ NMR (DMSO- $d_{\sigma}, \delta$ ppm, $300 \mathrm{MHZ}$ ): 9.21 (s, $1 \mathrm{H}, 9.21), 2.51$ (s, $\left.3 \mathrm{H}, \mathrm{CH}_{3}\right), 7.61-7.83(3 \mathrm{H}$, Aryl-H), 8.91(d, Quinolinyl H-2), 7.55 (d, Quinolinyl H-3), 8.11 (d, Quinolinyl H-4), 7.91 (d, Quinolinyl H-6), 7.34 (d, Quinolinyl H-7); LC-MS (\% area); 99.84; $\mathrm{m} / \mathrm{z}$; $342.18(\mathrm{M}+1)$; Analysis for $\mathrm{C}_{16} \mathrm{H}_{12} \mathrm{BrN}_{3} \mathrm{O}$ : Calcd \% C, 56.16; H, 3.53; N, 12.38; Found \%: C, 56.14; H, 3.55; $\mathrm{N}, 12.40$.

Bis 8, 8' [5-((3-nitrophenyl) diazenyl) quinolinium] copper $\left(\mathbf{4} \mathbf{a} \mathbf{L i g}_{2} \mathbf{C u}\right)$ : Coffee red colour; Yield $83 \% ; \mathrm{R}_{\mathrm{f}} ; 0.8$, mp $\left({ }^{\circ} \mathrm{C}\right)$; 293-295; UV-vis $\left(\lambda_{\max }, \mathrm{nm}, \mathrm{DMSO}\right): 440$; IR $\left(\mathrm{KBr}, \gamma, \mathrm{cm}^{-1}\right): 1639$ (C=N str. Quinolinyl), $1580(\mathrm{C}=\mathrm{C}$ str.), 1504 (-N=N-), 1338 ( $\mathrm{NO}_{2}$ str.), 546 (M-O), 488 (M-N); ${ }^{1} \mathrm{H}$ NMR (DMSO- $d_{6}, \delta$ ppm, 300 MHZ): 8.69 (s, 1H, 3-nitro phenyldiazenyl H-2), 8.41(d, 1H, 3-nitro phenyldiazenyl H-4), 7.88 ( $\mathrm{m}, 1 \mathrm{H}, 3$-nitro phenyldiazenyl H-5), 8.38 (d, 1H, 3-nitro phenyldiazenyl H-6), 9.31(d, 1H, Quinolinyl H-2), 8.13(m, 1H, Quinolinyl H-3), 9.10 (d, 1H, Quinolinyl H-4), 7.79(d, 1H, Quinolinyl H-6), 7.22 (d, 1H, Quinolinyl H-7); LC-MS (\% area); 91.73; $\mathrm{m} / \mathrm{z} ; 651.01(649.06)(\mathrm{M}+1)$; Analysis for: $\mathrm{C}_{30} \mathrm{H}_{18} \mathrm{CuN}_{8} \mathrm{O}_{62+}$ : Calcd \% C, 55.43; H, 2.79; Cu, 9.78; N, 17.24; Found \%: C, 55.45; H, 2.81; Cu, 9.81; N, 17.21.

Bis 8, $8^{\prime}$ [5-((3-nitrophenyl) diazenyl) quinolinium] cobalt (4a $\left.\mathbf{L i g}_{2} \mathrm{Co}\right)$ : Black colour; Yield $87 \% ; \mathrm{R}_{\mathrm{f}} ; 0.5$, $\mathrm{mp}\left({ }^{\circ} \mathrm{C}\right)$; 291-293; UV-vis ( $\lambda$ max, nm, DMSO): 457; IR $\left(\mathrm{KBr}, \gamma, \mathrm{cm}^{-1}\right): 1638$ (C=N str. Quinolinyl), $1584(\mathrm{C}=\mathrm{C}$ str.), , 1506 (-N=N-), 1332 ( $\mathrm{NO}_{2}$ str.), 545 (M-O), 438 (M-N); ${ }^{1} \mathrm{H}$ NMR (DMSO- $d_{6}, \delta$ ppm, 300 MHZ): 8.71 (s, 1H, 3-nitro phenyldiazenyl H-2), 8.41(d, 1H, 3-nitro phenyldiazenyl H-4), 7.89 ( $\mathrm{m}, 1 \mathrm{H}, 3$-nitro phenyldiazenyl H-5), 8.38 (d, 1H, 3-nitro phenyldiazenyl H-6), 9.29(d, 1H, Quinolinyl H-2), 8.11(m, 1H, Quinolinyl H-3), 9.12 (d, 1H, Quinolinyl H-4), 7.78 (d, 1H, Quinolinyl H-6),
7.19 (d, 1H, Quinolinyl H-7); LC-MS (\% area); 89; $\mathrm{m} / \mathrm{z}$; 644.13 (645.07) (M-1); Analysis for: $\mathrm{C}_{30} \mathrm{H}_{18} \mathrm{CoN}_{8} \mathrm{O}_{62+}$ : Calcd \% C, 55.83; H, 2.81; Co, 9.13; N, 17.36; Found \%: C, 55.84; H, 2.79; Co, 9.11; N, 17.33.

Bis 8, 8' [5-((3-nitrophenyl) diazenyl) quinolinium] nickel (4a $\mathbf{L i g}_{2} \mathbf{N i}$ ): Coffee red colour; Yield $91 \%$; $\mathrm{R}_{\mathrm{f}}$; 0.8, mp $\left({ }^{\circ} \mathrm{C}\right)$; 292-295; UV-vis ( $\lambda_{\text {max }}$, nm, DMSO): 462; IR ( $\left.\mathrm{KBr}, \gamma, \mathrm{cm}^{-1}\right)$ : $1648(\mathrm{C}=\mathrm{N}$ str. Quinolinyl), 1581 (C=C str.), 1504 (-N=N-), $1337\left(\mathrm{NO}_{2}\right.$ str.), 505 (M-O), 440 (M-N); ${ }^{1} \mathrm{H}$ NMR (DMSO- $d_{6}, \delta$ ppm, 300 MHZ): 8.73 (s, 1H, 3-nitro phenyldiazenyl H-2), 8.43(d, $1 \mathrm{H}, 3$-nitro phenyldiazenyl $\mathrm{H}-4), 7.89$ (m, $1 \mathrm{H}, 3$-nitro phenyldiazenyl $\mathrm{H}-5), 8.36$ (d, 1H, 3-nitro phenyldiazenyl H-6), 9.33(d, 1H, Quinolinyl H-2), 8.13(m, 1H, Quinolinyl H-3), 9.13 (d, 1H, Quinolinyl H-4), 7.77(d, 1H, Quinolinyl H-6), 7.23 (d, 1H, Quinolinyl H-7); LC-MS (\% area); 86.19; $\mathrm{m} / \mathrm{z} ; 645.29$ (644.07) (M+1); Analysis for: $\mathrm{C}_{30} \mathrm{H}_{18} \mathrm{~N}_{8} \mathrm{NiO}_{62+}$ : Calcd \% C, 55.85; H, 2.81; N, 17.37; Ni, 9.10; Found \%: C, 55.87; H, 2.83; Ni, 9.11; N, 17.38 .0

Bis 8, 8' [5-((4-bromo-3-methylphenyl) diazenyl) quinolinium] copper $\left(\mathbf{4} \mathbf{b} \mathbf{~ L i g}_{2} \mathbf{C u}\right)$ : Brick red colour; Yield 85 $\%$; $\mathrm{R}_{\mathrm{f}}$; 0.6, mp $\left({ }^{\circ} \mathrm{C}\right)$; 284-286; UV-vis ( $\left.\lambda_{\max }, \mathrm{nm}, \mathrm{DMSO}\right)$ : 415; IR ( $\left.\mathrm{KBr}, \gamma, \mathrm{cm}^{-1}\right): 2920\left(\mathrm{CH}_{2}\right.$ str. $\left.\mathrm{CH}_{3}\right), 1567(\mathrm{C}=\mathrm{N}$ str. Quinolinyl), $1501(-\mathrm{N}=\mathrm{N}-), 701$ (C-Br), 884 (1, 2, 4 trisubst. Ar), 527 (M-O), 451 (M-N); ${ }^{1} \mathrm{H}$ NMR (DMSO- $d_{6}, \delta$ ppm, $300 \mathrm{MHZ}$ ): 2.33 (s, 3H, $\mathrm{CH}_{3}$ ), 7.76 (s, 1H, 4-bromo-3-methyldiazenyl, H-2), 7.64 (d, 1H, 4-bromo-3-methyldiazenyl, H-5), 7.65 (d, 1H, 4-bromo3-methyldiazenyl, H-6), 9.25 (d, Quinolinyl H-2), 8.29 (m, Quinolinyl H-3), 8.90 (d, Quinolinyl H-4), 8.00 (d, Quinolinyl H-6), 7.26 (d, Quinolinyl H-7); LC-MS (\% area); 87.34; $\mathrm{m} / \mathrm{z} ; 744.96(744.94)(\mathrm{M}+2)$; Analysis for $\mathrm{C}_{32} \mathrm{H}_{22} \mathrm{Br}_{2} \mathrm{CuN}_{6} \mathrm{O}_{22+}$ : Calcd \% C, 51.53; H, 2.97; Br, 21.42; Cu, 8.52; N, 11.27; Found \%: C, 51.48; H, 2.94; $\mathrm{Br}, 21.44 ; \mathrm{Cu}, 8.55 ; \mathrm{N}, 11.32$.

Bis 8, 8' [5-((4-bromo-3-methylphenyl) diazenyl) quinolinium] cobalt (4b $\left.\operatorname{Lig}_{2} \mathrm{Co}\right)$ : Brick red colour; Yield 81 $\%$; $\mathrm{R}_{\mathrm{f}} ; 0.5, \mathrm{mp}\left({ }^{\circ} \mathrm{C}\right) ; 278-281$; UV-vis $\left(\lambda_{\max }, \mathrm{nm}, \mathrm{DMSO}\right)$ : 473; IR ( $\left.\mathrm{KBr}, \gamma, \mathrm{cm}^{-1}\right): 2922\left(\mathrm{CH}_{2}\right.$ str. $\left.\mathrm{CH}_{3}\right), 1573(\mathrm{C}=\mathrm{N}$ str. Quinolinyl), 1499 (-N=N-), 711 (C-Br), 885 (1, 2, 4 trisubst. Ar), 510 (M-O), 431 (M-N),; ${ }^{1} \mathrm{H}$ NMR (DMSO- $d_{6}, \delta$ ppm, $\left.300 \mathrm{MHZ}\right): 2.35\left(\mathrm{~s}, 3 \mathrm{H}, \mathrm{CH}_{3}\right), 7.79$ (s, 1H, 4-bromo-3-methyldiazenyl, H-2), 7.67 (d, 1H, 4-bromo-3-methyldiazenyl, H-5), 7.68 (d, 1H, 4-bromo3-methyldiazenyl, H-6), 9.19 (d, Quinolinyl H-2), 8.12 (m, Quinolinyl H-3), 9.03 (d, Quinolinyl H-4), 7.89 (d, Quinolinyl H-6), 7.19 (d, Quinolinyl H-7); LC-MS (\% area); 99.34; $\mathrm{m} / \mathrm{z} ; 739.3$ (740.95) (M-1); Analysis for $\mathrm{C}_{32} \mathrm{H}_{22} \mathrm{Br}_{2} \mathrm{CoN}_{6} \mathrm{O}_{22+:}$ Calcd \% C, 51.85; H, 2.99; $\mathrm{Br}$, 21.56; Co, 7.95; N, 11.34; Found \%: C, 51.87; H, 2.97; Br, 21.53; Co, 7.94; N, 11.32. 
Bis 8, 8' [5-((4-bromo-3-metbylphenyl) diazenyl) quinolinium] nickel (4b $\left.\mathbf{L i g}_{\mathbf{2}} \mathbf{N i}\right)$ : Brick red colour; Yield 91 $\% ; \mathrm{R}_{\mathrm{f}} ; 0.7, \mathrm{mp}\left({ }^{\circ} \mathrm{C}\right) ; 282-284$; UV-vis $\left(\lambda_{\max }, \mathrm{nm}, \mathrm{DMSO}\right)$ : 405; IR $\left(\mathrm{KBr}, \gamma, \mathrm{cm}^{-1}\right): 2921\left(\mathrm{CH}_{2}\right.$ str. $\left.\mathrm{CH}_{3}\right), 1566(\mathrm{C}=\mathrm{N}$ str. Quinolinyl), 1463 (-N=N-), 702 (C-Br), 884 (1, 2, 4 trisubst. Ar), 566 (M-O), $471(\mathrm{M}-\mathrm{N}) ;{ }^{1} \mathrm{H}$ NMR (DMSO- $d_{6}, \delta$ ppm, $\left.300 \mathrm{MHZ}\right): 2.31$ (s, $\left.3 \mathrm{H}, \mathrm{CH}_{3}\right), 7.73$ (s, 1H, 4-bromo-3-methyldiazenyl, H-2), 7.71 (d, 1H, 4-bromo-3-methyldiazenyl, H-5), 7.64 (d, 1H, 4-bromo3-methyldiazenyl, H-6), 9.21(d, Quinolinyl H-2), 8.57 (m, Quinolinyl H-3), 8.98 (d, Quinolinyl H-4), 7.85 (d, Quinolinyl H-6), 7.19 (d, Quinolinyl H-7); LC-MS (\% area); 99.12; m/z; 739.3 (739.95) (M+); Analysis for $\mathrm{C}_{32} \mathrm{H}_{22} \mathrm{Br}_{2} \mathrm{~N}_{6} \mathrm{NiO}_{22+}$ : Calcd \% C, 51.86; H, 2.99; Br, 21.56; N, 11.34; Ni, 7.92; O, 4.32; Found \%: C, 51.82; H, 2.97; Br, 21.58; Ni, 7.91; N, 11.31.

\section{SCHEME-1}

\section{Antimicrobial Evaluation}

The above newly synthesized metal complexes of 8-hydroxyquinolineazo analogues were investigated over different freshly sub cultured microbial strains viz. Escherichia coli (MTCC 614), Klebsiella pneumonia (MTCC 109) and Candida albicans (MTCC 3017) were procured from the Institute of Microbial Technology and Gene bank (IMTECH), Chandigarh, India. Staphylococcus aureus and Cryptococcus neoformans were obtained from University Department of Pharmaceutical Sciences, Utkal University. Ampicillin and fluconazole were used as reference antibiotics for bacterial and fungal strains respectively. Employing McFarland turbidity standard No. 0.5 , the antimicrobial diffusion
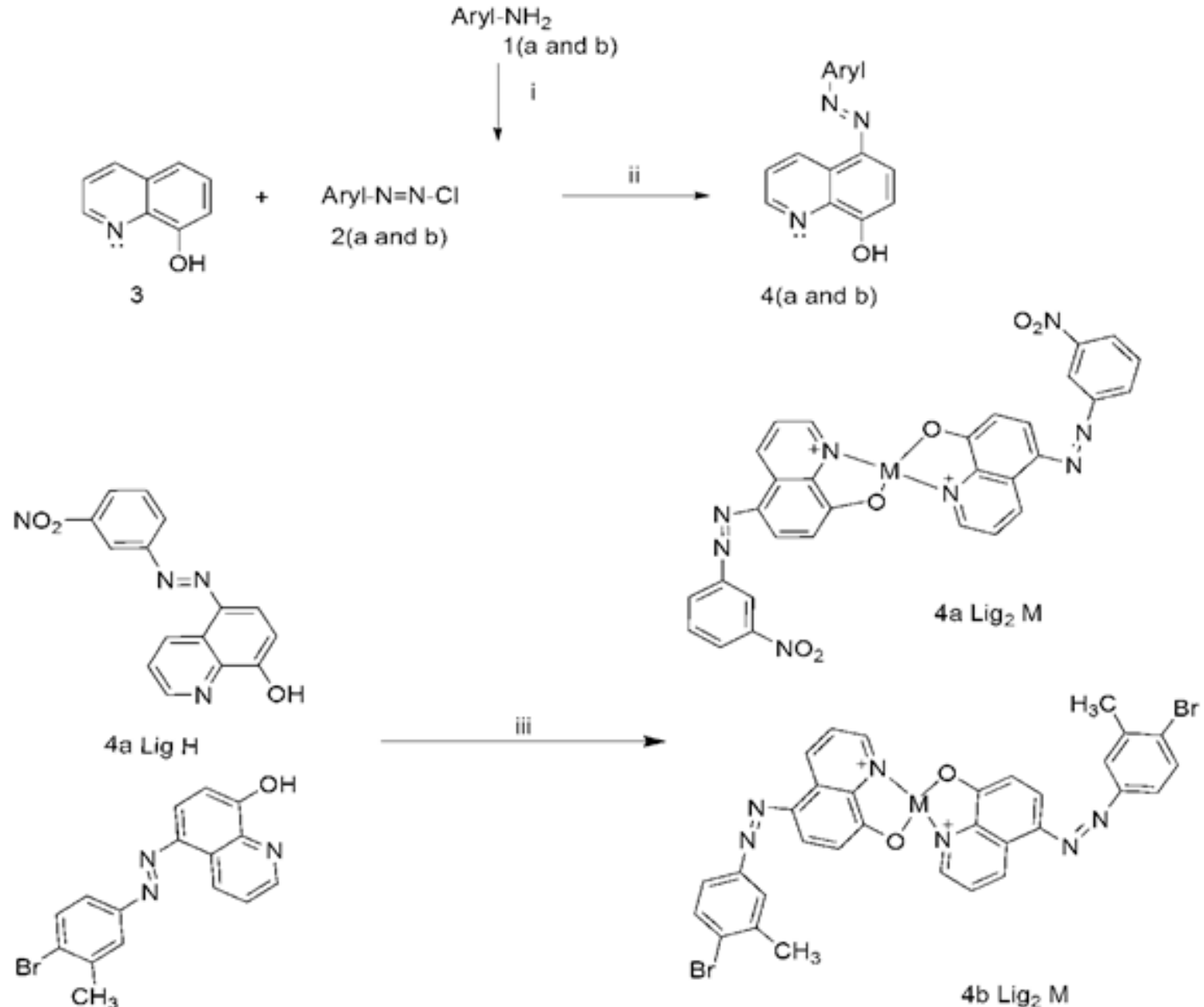

4b Lig H

$\mathrm{M}=\mathrm{Cu}(\mathrm{II}), \mathrm{Co}(\mathrm{II}), \mathrm{Ni}(\mathrm{II})$

Reaction :- i. $\mathrm{NaNO}_{2} / \mathrm{HCl}, 0-5^{\circ} \mathrm{C}$, diazotization ii. $\mathrm{NaOH} /$ acetate buffer 30 min coupling reaction Aryl $\mathrm{NH}_{2}$; 3- nitro phenyl- (4a), 4-bromo,3-methyl phenyl-(4b) iii. $\mathrm{MCl}_{2} \times \mathrm{H}_{2} \mathrm{O}$ / ethanol reflux $30 \mathrm{~min}$ at $75^{\circ} \mathrm{C}$ 
assay was performed using a cell suspension of about $1.5 \times 10^{6} \mathrm{CFU} \mathrm{mL} \mathrm{m}^{-1}$. The antimicrobial activity of the novel metal complexes of 8-hydroxyquinolineazo analogues were performed by agar well diffusion method using sterile molten nutrient agar and Sabouraud dextrose agar medium respectively for antibacterial and antifungal investigation. ${ }^{28}$ The diameter of zone of inhibition was measured using the Hi-Antibiotic Zone Scale (Hi-Media). Each test compound was screened six times against individual strains.

\section{Minimum inhibitory concentration (MIC)}

A stock solution of synthesized compounds at a concentration level of $1 \mathrm{mgmL}^{-1}$ and reference antibiotics was prepared using DMF. Further, five different concentrations of (500-31.25 $\left.\mu \mathrm{gmL}^{-1}\right)$ were prepared by serial dilution fold dilution method. Further the different concentrations prepared from respective compounds were loaded into the wells and incubated at $37^{\circ} \mathrm{C}$ for $18-24 \mathrm{~h}$. After incubation MIC was determined. ${ }^{29}$

\section{Statistical analysis}

The observed data on zone of inhibitions were subjected to one way- analysis of variance. Through Dunnett Post Hoc test (https://www.statstodo.com/SSizAOV_Pgm. php) Mean zone of inhibition for each compound on each strain was compared with the reference antibiotic. The test of significance was done at 5\% level of type one error. The research hypothesis was 'the zone of inhibition for test compound was higher than the reference antibiotic against the hypothesis of no difference (null hypotheses) which states that there is no significant difference between the zone of inhibition of the test compound and reference antibiotics.

\section{Sample size determination}

A minimum sample size of five was calculated taking probability of type 1 error $(d)=0.05$, Power $(1-\beta)=0.8$, Number of groups 13 within group $S D=2$. However a sample size of six has been taken in the study for each compound against each strain.

\section{RESULTS AND DISCUSSION}

\section{Chemistry}

The synthesis of compounds 5-((3-nitrophenyl) diazenyl) quinolin-8-ol (4a) and 5-((4-bromo-3-methylphenyl) diazenyl) quinolin-8-ol (4b) were earlier reported ${ }^{5}$. These both ligands are prepared by the coupling of mixture of diazotised substituted primary aromatic amine with 8-hydroxy quinoline in mild condition. Further, the transitional metal complexes analogues were synthesized by the addition of respective metal chlorides to alcoholic solution of the ligands. The mixture was refluxed and finally the obtained complexes were re-crystallized from diethyl ether (Scheme-1).

The elemental analysis of all the compounds shows good agreement with their calculated values.

The FT/IR spectra gave valuable information regarding the location of different functional groups attached to the metals. The spectrum of the ligands $4 a$ and $4 b$ showed vibration band at range of 3432 and $3290 \mathrm{~cm}^{-1}$ which attributed to $\nu \mathrm{OH}$ str. group of $8-\mathrm{HQ}$. The bands appeared at 1506 and $1503 \mathrm{~cm}^{-1}$ in the ligands corresponds to $\nu-\mathrm{N}=\mathrm{N}$ - str. All the complexes showed the vibration bands at a range of $1506-1463 \mathrm{~cm}^{-1}$ which corresponds to $\nu-\mathrm{N}=\mathrm{N}$ - str. A new set of frequency bands observed at the region of $566-500 \mathrm{~cm}^{-1}$ and 488 $431 \mathrm{~cm}^{-1}$ corresponding to $\vee \mathrm{M}-\mathrm{O}$ and $\nu \mathrm{M}-\mathrm{N}$ in all the complexes respectively. The FT/IR absorption band of hydroxyl group of 8-HQ at 3432-3290 $\mathrm{cm}^{-1}$ in respective ligands $4 \mathbf{a}$ and $\mathbf{4 b}$ has been found to be diminished in all their respective complexes which indicates that the 8-hydroxyquinoline azo analogue $(\mathbf{4 a}$ and $\mathbf{4 b})$ has been reacted with metal chloride and subsequently deprotonation and co-ordinate the metal with 1,8 position of quinoline. However there is no significant changes in the vibration bands of $\nu-\mathrm{N}=\mathrm{N}$ - (azo group) is found to be observed in the ligands and their respective com-

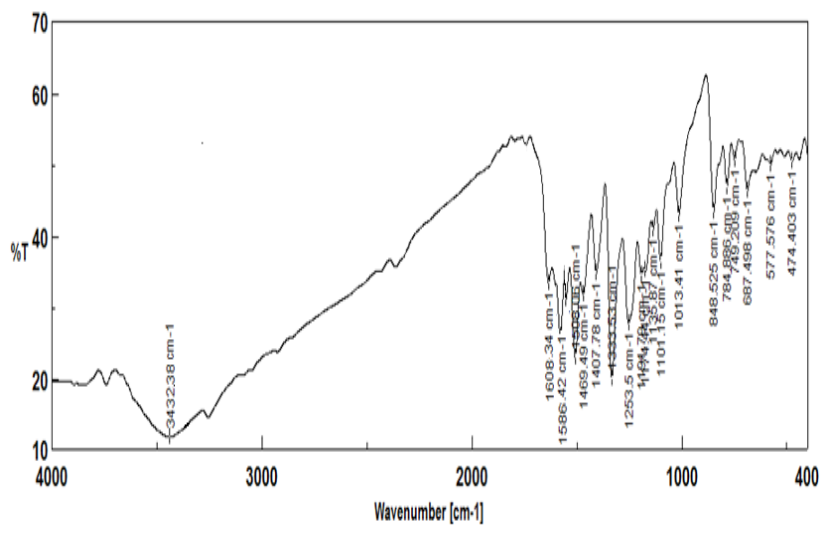

Figure 1: FT/IR spectra of 5-((3-nitrophenyl) diazenyl) quinolin-8-ol (4a).

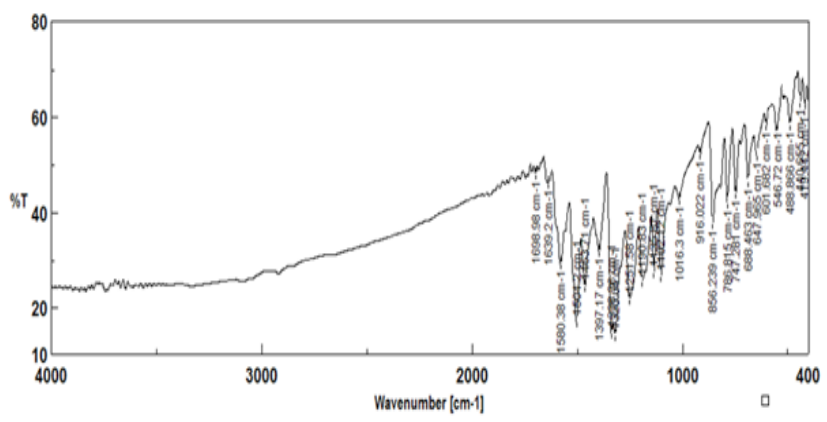

Figure 2: FT/IR spectra of bis 8, 8' [5-((3-nitrophenyl) diazenyl) quinolinium] copper $\left(4 \mathrm{a} \mathrm{Lig}_{2} \mathrm{Cu}\right)$. 
The $\lambda_{\max }$ of the synthesized compounds was measured on UV-Visible spectrophotometer. The absorption spectra of the compounds $\left(4 \mathbf{a}, 4 \mathbf{b}, \mathbf{4 a ~} \mathbf{L i g}_{2} \mathbf{M}\right.$ and $\left.4 \mathrm{~b} \mathrm{Lig}_{2} \mathrm{M}\right)$ were measured at a concentration of $10^{-5}$ to $10^{-6} \mathrm{M}$, in the region $200-600 \mathrm{~nm}$ using DMSO as a solvent. The UV-Visible spectra of the ligand $\mathbf{4 a}$ showed the $\lambda_{\text {max }}$ at $463 \mathrm{~nm}$ whereas its transitional metal complexes with $\mathbf{C u}(\mathbf{I I})$ and $\mathbf{C o}(\mathrm{II})$ showed at 440 and $457 \mathrm{~nm}$ respectively. However there is no significant change in the $\lambda_{\text {max }}$ of the ligand $\mathbf{4 a}$ and its metal complex $\left(\mathbf{4 a L i g}_{\mathbf{2}} \mathbf{N i}\right)$ is found to be observed. The ligand $\mathbf{4 b}$ showed the $\lambda_{\max }$ at $404 \mathrm{~nm}$ whereas its complexes with $\mathbf{C u}(\mathrm{II})$ and $\mathbf{C o}(\mathrm{II})$ showed bathochromic shift at 415 and $473 \mathrm{~nm}$ respectively. There is no considerable difference in $\lambda_{\text {max }}$ found to be observed in compound $4 b$ and its metal complex $4 \mathbf{b L i g}_{2} \mathbf{N i}$. The observed $\lambda_{\max }$ by the synthesized ligand $\mathbf{4 b}$ and its complexes suggested that insertion of $\mathrm{Cu}(\mathrm{II})$ and $\mathrm{Co}(\mathrm{II})$ to ligand $\mathbf{4 b}$ may be responsible for showing bathochromic shift. Interestingly it is found to be observed that when the metals are attached with 3-nitrophenyl conjugated 8-HQ azo

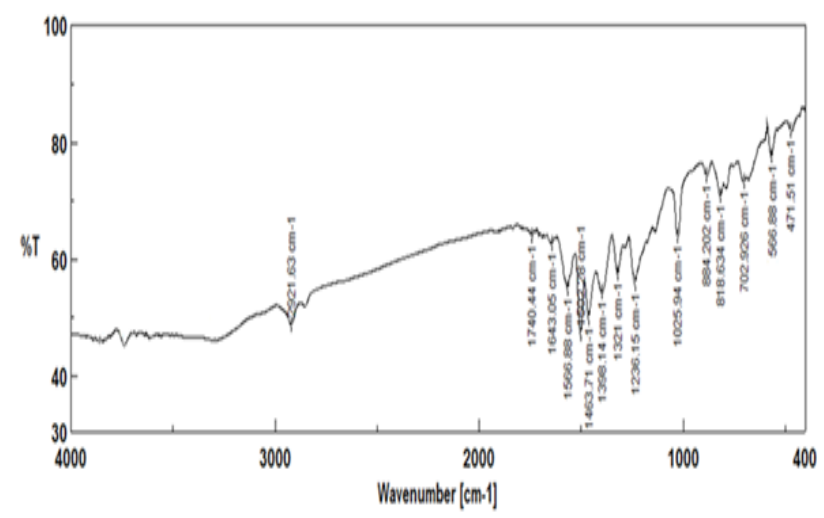

Figure 3: FT/IR spectra of bis 8, 8' [5-((4-bromo-3-methylphenyl) diazenyl) quinolinium] nickel ( $\left.4 \mathrm{~b} \mathrm{Lig}_{2} \mathrm{Ni}\right)$.

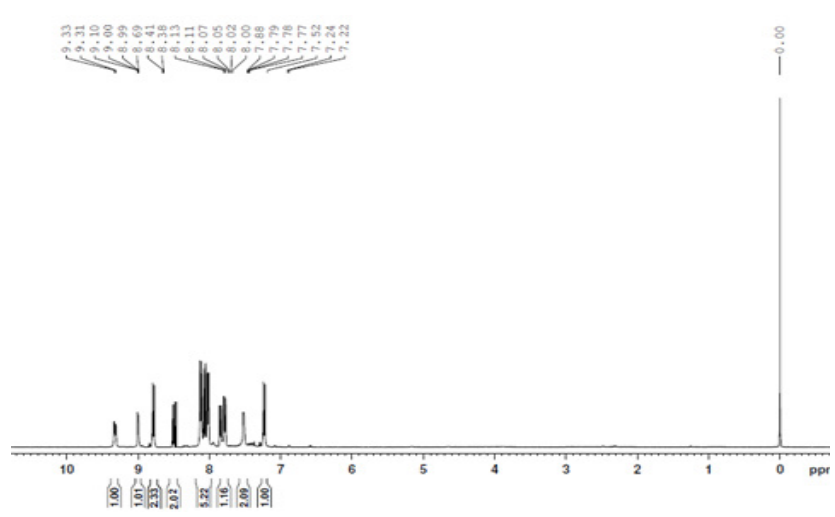

Figure 4: 'H NMR spectra of bis 8, 8' [5-((3-nitrophenyl) diazenyl) quinolinium] copper ( $\left.4 \mathrm{a} \mathrm{Lig}_{2} \mathrm{Cu}\right)$. plexes may be due to non involvement of azo moiety with metal ions. The FT/IR spectra of ligand $\mathbf{4 a}, \mathbf{4 a}$ $\operatorname{Lig}_{2} \mathrm{Cu}$ and $4 \mathrm{~b} \mathrm{\operatorname {Lig } _ { 2 }} \mathrm{Cu}$ is depicted in Figure 1, Figure 2 and Figure 3 respectively.

All the synthesized compounds showed five quinoline aromatic protons with a range of $\delta 7.19-9.33 \mathrm{ppm}$ in their ${ }^{1} \mathrm{H}$ NMR spectral data. The ${ }^{1} \mathrm{H}$ NMR spectra of synthesized the ligands $4 \mathbf{a}$ and $\mathbf{4 b}$ showed a broad singlet peak at $\delta 9.67$ and $9.21 \mathrm{ppm}$, corresponding to hydroxyl group of 8-hydroxyquinoline whereas, the quinoline protons with a range of $\delta 7.33-9.11 \mathrm{ppm}$. In all the complexes, the broad singlet peak due to hydroxyl group of 8-HQ is found to be abolished which indicates deprotonation and co-ordination of metal and oxygen of the ligands. In all the complexes of ligand $\mathbf{4 a}$, the 3-nitrophenyldiazenyl $\mathrm{H}-2$ proton showed at a range of $\delta 8.73-8.69 \mathrm{ppm}$. Similarly, in all the complexes of ligand $4 \mathrm{~b}$, the methyl proton showed the singlet at $\delta$ 2.31-2.35 ppm. The ${ }^{1} \mathrm{H}$ MNR spectra of the complexes $\mathbf{4 a L i g}_{2} \mathrm{Cu}$ and $\mathbf{4 b L i g}_{2} \mathbf{N i}$ is illustrated in Figure 4 and Figure 5.

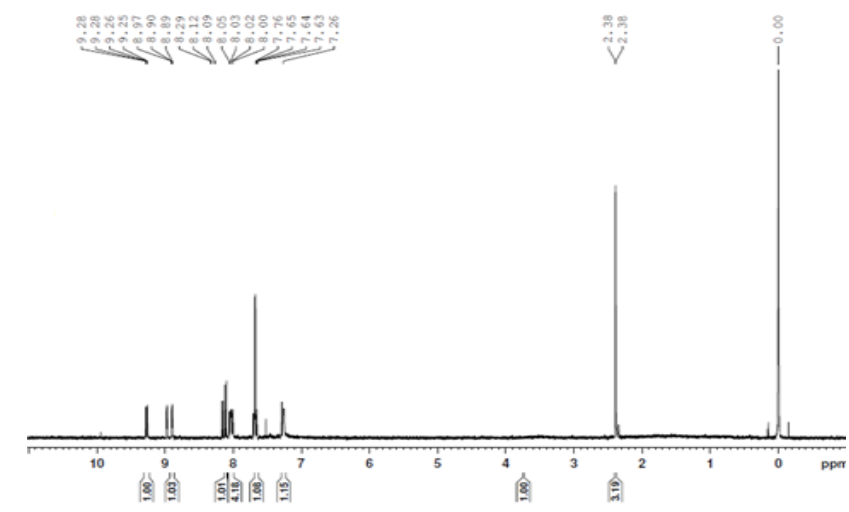

Figure 5: ${ }^{1} \mathrm{H}$ NMR spectra of bis $8,8^{\prime}$ [5-((4-bromo-3-methylphenyl) diazenyl) quinolinium] nickel (4b $\left.\mathrm{Lig}_{2} \mathrm{Ni}\right)$.
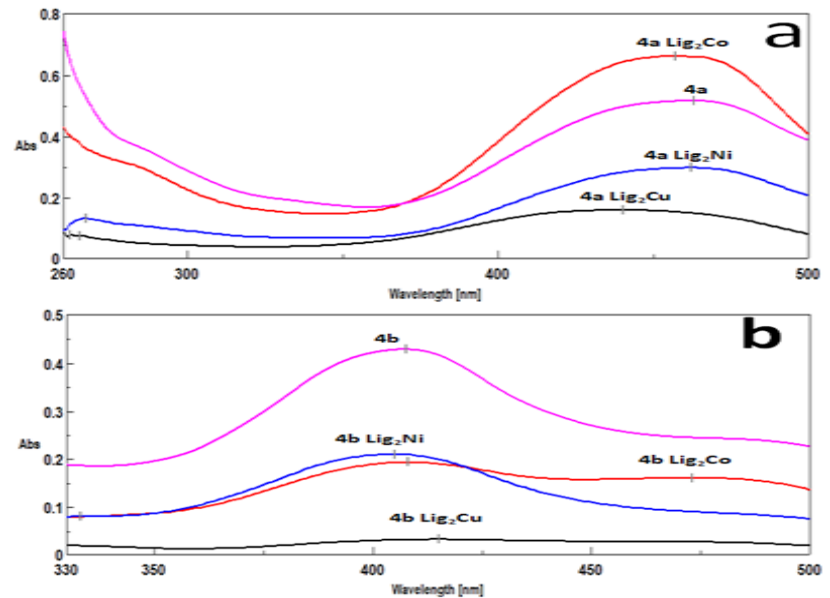

Figure 6: Overlay in UV-Visible spectra of ligands $4 a$ and $4 b$ with their metal complexes respectively using DMSO as a solvent. 
analogue (4a), the $\lambda_{\text {max }}$ showed by the complexes found to be less than the lignd $\mathbf{4 a}$ at the same time the metals when attached with 4-bromo-3-methyl conjugated 8-HQ azo analogue (4b) they showed a good bathochromic shift than their ligand $4 \mathrm{~b}$. Somehow this may be due to the nature of different functionalities present in the synthesized complexes. The overlay in UV-Visible spectra of the ligands and their respective metal complexes is illustrated in Figure 6.

\section{Magnetic susceptibility and LC-MS study}

The magnetic susceptibility of $\mathbf{C o}(\mathrm{II})$ complexes at room temperature lies at a range 5.07 and $4.93 \mathrm{BM}$ for $4 \mathrm{a} \mathrm{Lig}_{2} \mathrm{Co}$ and $4 \mathrm{~b} \operatorname{Lig}_{2} \mathrm{Co}$ respectively suggests the tetrahedral geometry. The $\mathbf{N i ( I I )}$ complexes for $\mathbf{4 a}$ $\mathbf{L i g}_{2} \mathbf{N i}$ and $4 \mathrm{~b} \mathrm{Lig}_{2} \mathbf{N i}$ showed magnetic moment at 2.97 and $3.09 \mathrm{BM}$ whereas $\mathbf{C u}(\mathbf{I I})$ complexes at 1.99 and $1.83 \mathrm{BM}$ respectively which is nearer to the reported value suggesting for the tetrahedral geometry. ${ }^{17,30}$ The compounds $4 \mathrm{a}$ and $\mathbf{4 b}$ act as bidentate ligand by chelating to transitional metal ions to establish the proposed structure (Scheme-1).

The predicted molecular weight of the synthesized ligands and their complexes was confirmed by LC-MS. The compound bis 8, 8' [5-((4-bromo-3-methylphenyl) diazenyl) quinolinium] nickel $\left(4 \mathbf{b} \mathbf{~ L i g}_{2} \mathbf{N i}\right.$ ) having molecular ion peak $739.3(\mathrm{M}+)$ strongly reveals the predicted molecular formula $\mathrm{C}_{32} \mathrm{H}_{22} \mathrm{Br}_{2} \mathrm{~N}_{6} \mathrm{NiO}_{22+}$ (Figure 7).

\section{Antimicrobial screening}

The antimicrobial activity of the synthesized compounds is investigated against $E$. coli, $K$. pneumonia, S. aureus, C. albicans and C. neoformans. The mean \pm S.D. of zone of inhibition for each microbial strain has been compared by one way-analysis of variance and the resulting $p$ value (Table 1). Most of the complexes showed better zone of inhibition than their ligands. However the complexes $\mathbf{4 a} \mathbf{L i g}_{2} \mathrm{Cu}$ and $\mathbf{4 b} \mathbf{L i g}_{2} \mathrm{Cu}$ showed excellent significant antimicrobial activity in comparison

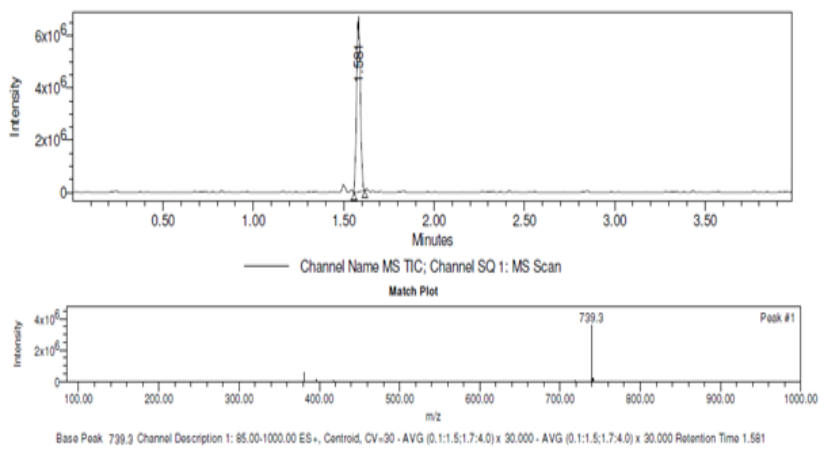

Figure 7: LCMS of bis 8, 8' [5-((4-bromo-3-methylphenyl) diazenyl) quinolinium] nickel (4b $\left.\mathrm{Lig}_{2} \mathrm{Ni}\right)$. to standard drugs. All the complexes showed potentially significant antimicrobial activity against $S$. aureus except $4 \mathrm{~b} \mathrm{Lig}_{2} \mathrm{Ni}$. However the gram positive bacterial strain $S$. aureus is found to be resistant towards the ligands $4 a$ and $4 b$. The enhancement of antimicrobial activity of the ligands may be due to chelation of transitional metals with them. Complexation reduces the polarity of metal ion by coordinating with ligands and increases the lipophilicity of the metals. ${ }^{31}$ Thus it facilitates the novel synthesized complex to penetrate the lipoid cell membrane of microorganisms and inhibit their growth. No compounds showed any effective antimicrobial activity against $C$. albicans. However it is found to be observed that when the ligands are complexed with the respective metals showed pronounced antimicrobial activity even more than that of the reference antibiotics used. In our earlier reported research it is found to be observed that the (3-nito phenyl and 4-bromo-3-methyl) 8-hydroxy quinoline azoanalogues showed no antimicrobial activity against $S$. aureus but when the same ligands coor-

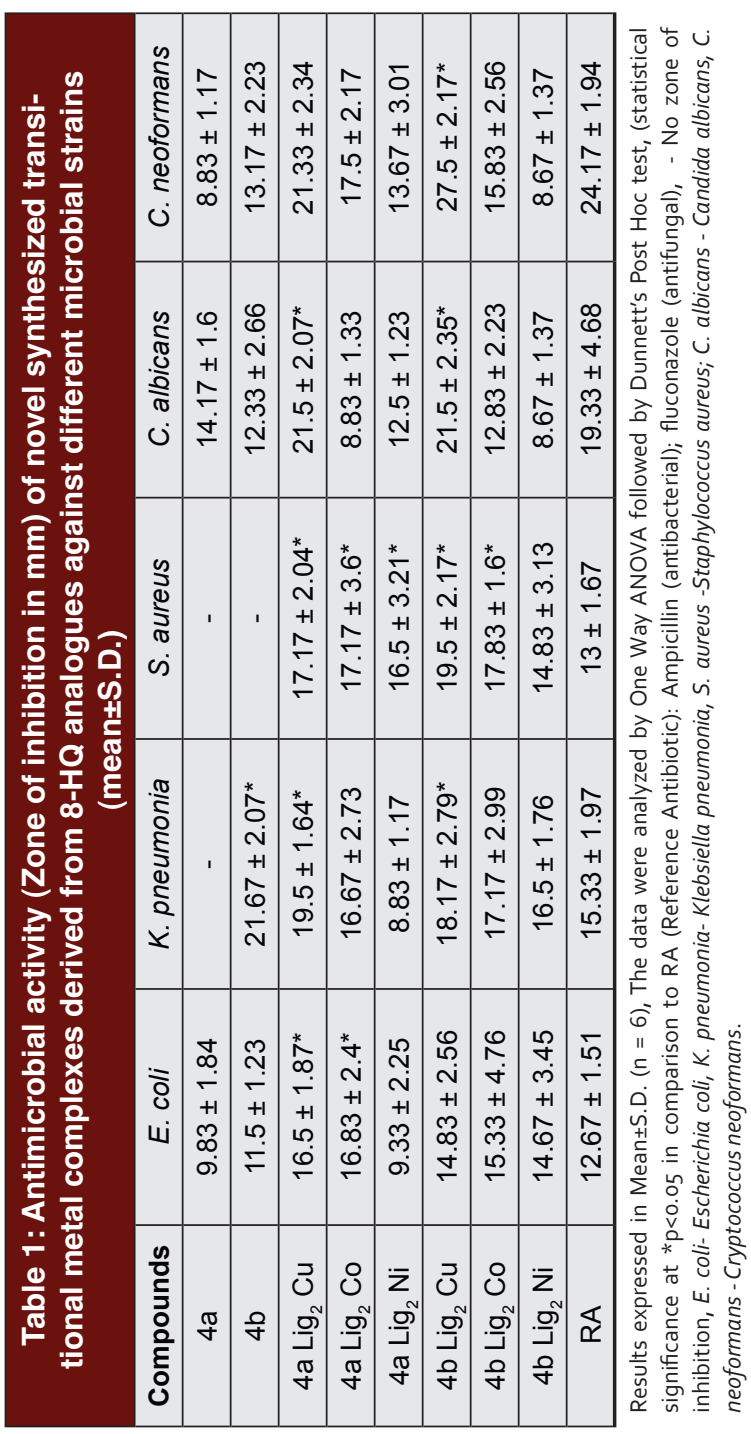


dinated with transitional metals showed tremendous significant antimicrobial activity. The antibiogram of the ligands $\mathbf{4 a}, \mathbf{4 b}$ and their complexes are presented in Figure 8. The statistical interpretation of the complexes $4 \mathrm{a} \mathrm{Lig}_{2} \mathrm{Cu}$ and $4 \mathrm{~b} \mathbf{L i g}_{2} \mathrm{Cu}$ against all the strains and the antimicrobial activity of all the compounds against $S$. aureus is explained with the help of error bars in Figure 9.
Minimum inhibitory concentrations

The inhibitory property of the novel synthesized 8-hydroxyquinolineazo analogues and their metal complexes was determined in terms of MIC $\left(\mu \mathrm{g} \mathrm{mL} \mathrm{m}^{-1}\right)$. The synthesized complexes $\mathbf{4} \mathrm{aLig}_{2} \mathrm{Cu}, \mathbf{4 a L i g}_{2} \mathrm{Co}$, $4 \mathrm{bLig}_{2} \mathrm{Cu}$ and $4 \mathrm{bLig}_{2} \mathrm{Co}$ exhibited potential antimicrobial activity by inhibiting the growth of different microbial strains at MIC level 31.25 $\mathrm{g} \mathrm{mL}^{-1}$. (Table 2).
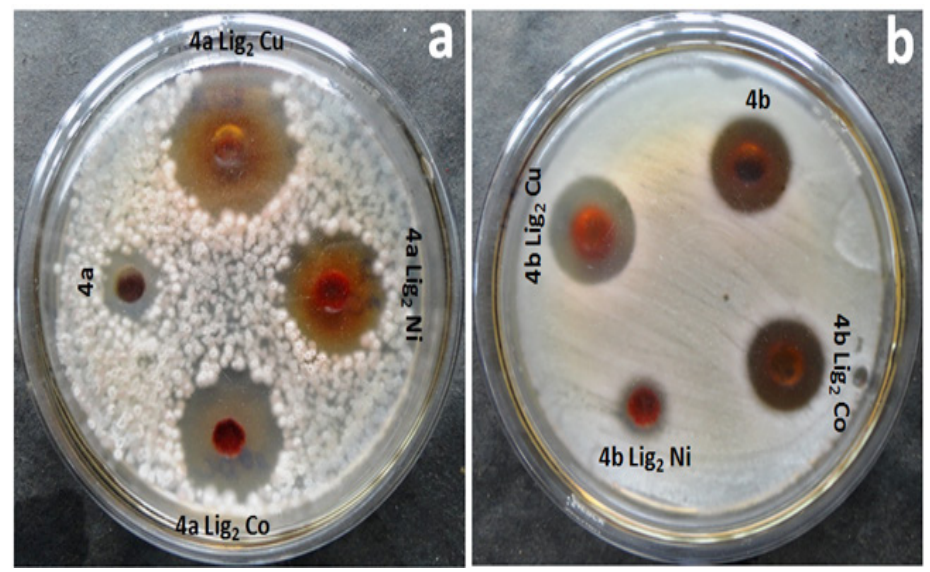

Figure 8: Antibiogram pattern of the transitional metal complexes of the ligands $4 \mathrm{a}$ and $4 \mathrm{~b}$ against $C$. neoformans and $C$. albicans respectively.
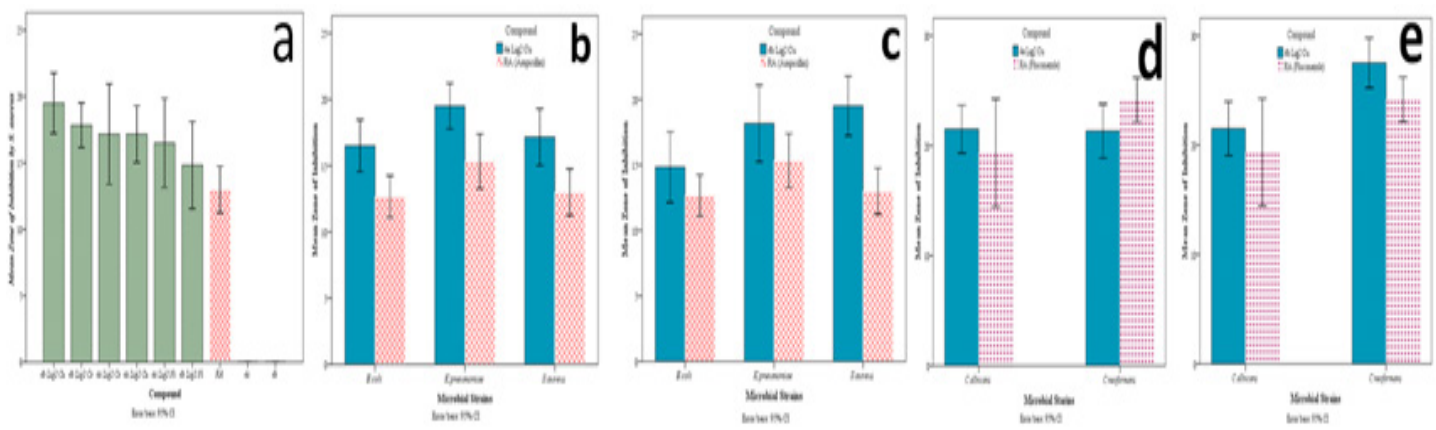

Figure 9: Statistically interpreted antimicrobial activity of [all the synthesized compounds against $S$. aureus (a), 2 alig $_{2} \mathrm{Cu}$ and $2 \mathrm{bLig}_{2} \mathrm{Cu}$ against different bacterial strains (b and c) respectively and $2 \mathrm{alig}_{2} \mathrm{Cu}$ and $2 \mathrm{bLig}_{2} \mathrm{Cu}$ against different fungal strains ( $d$ and $e$ ) respectively] with the help of error bars.

\begin{tabular}{|c|c|c|c|c|c|}
\hline Compounds & E. coli & K. pneumonia & S. aureus & C. albicans & C. neoformans \\
\hline $4 a$ & $>500$ & - & - & 125 & 500 \\
\hline $4 b$ & 125 & 31.25 & - & 125 & 125 \\
\hline $4 \mathrm{a} \mathrm{Lig}_{2} \mathrm{Cu}$ & 31.25 & 31.25 & 31.25 & 31.25 & 31.25 \\
\hline 4a $\operatorname{Lig}_{2}$ Co & 31.25 & 31.25 & 31.25 & 500 & 31.25 \\
\hline $4 \mathrm{a} \mathrm{Lig}_{2} \mathrm{Ni}$ & 500 & $>500$ & 31.25 & 125 & 125 \\
\hline 4b $\mathrm{Lig}_{2} \mathrm{Cu}$ & 31.25 & 31.25 & 31.25 & 31.25 & 31.25 \\
\hline 4b $\mathrm{Lig}_{2} \mathrm{Co}$ & 31.25 & 31.25 & 31.25 & 125 & 31.25 \\
\hline 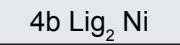 & 62.5 & 31.25 & 62.5 & $>500$ & $>500$ \\
\hline
\end{tabular}

- No zone of inhibition, E. coli- Escherichia coli, K. pneumonia- Klebsiella pneumonia, S. aureus -Staphylococcus aureus; C. albicans - Candida albicans, C. neoformans - Cryptococcus neoformans. 


\section{CONCLUSION}

This research work comprises of the synthesis of a series of six complexes with their two respective ligands (4a) 5-((3-nitrophenyl) diazenyl) quinolin-8-ol and (4b) 5-((4-bromo-3-methylphenyl) diazenyl) quinolin-8-ol. The synthesized complexes bis 8,8 ' [5-((3-nitrophenyl) diazenyl) quinolinium] copper $\left(\mathbf{4 a L i g}_{2} \mathbf{C u}\right)$ and bis $8,8^{\prime}$ [5-((4-bromo-3-methylphenyl) diazenyl) quinolinium] copper $\left(\mathbf{4} \mathrm{b}_{\mathbf{L i g}} \mathrm{Cu}\right)$ showed significant antimicrobial activity against most of the microbial strains. The observed antimicrobial effect reveals a strong structure activity relationship between the ligands and their respective complexes. It is found that introduction of transition metal $\mathbf{C u}(\mathrm{II})$ to the above synthesized ligands may be responsible for exhibiting excellent antimicrobial activity against different microbial strains than the parent noncomplex ligands. Though other metal complexes also showed potential antimicrobial activities but particularly the $\mathbf{C u}(\mathbf{I I})$ attached ligands showed significant antimicrobial activities in comparison to the standard.

\section{ACKNOWLEDGEMENTS}

The authors are indebtly acknowledge to the Dean, School of Pharmaceutical Sciences, Siksha 'O' Anusandhan University, Director of NISER, IMMT, and Dr. Bijaya Bhusan Nanda, Deputy Director Regional Institute of Planning, Applied Economics and Statistics, Bhubaneswar, India. The Chairman and Principal of Sri Jayadev College of Pharmaceutical Sciences, Bhubaneswar is also acknowledged for their constant inspiration to pursue this research.

\section{CONFLICT OF INTEREST}

The authors have no conflict of interest.

\section{ABBREVIATION USED}

WHO: World Health Organization; 8-HQ: 8-Hydroxy quinoline; FT/IR: Fourier transform infrared spectroscopy; UV-Vis: Ultra violet visible spectroscopy; NMR: Nuclear magnetic resonance spectroscopy; LC-MS: Liqid chromatography and mass spectrometry; TLC: Thin layer chromatography; Lig: Ligand; BM: Bohr magneton; MIC: Minimum inhibitory concentration; MTCC: Microbial type culture collection; IMTECH: Institute of microbial technology; CFU: Colony forming unit; DMSO: Dimethyl sulphoxide; RA: Reference antibiotic.

\section{REFERENCES}

1. http://www.tufts.edu/med/apua/consumers/personal_home_5_1451036133.

2. Albrecht M, Fiege M, Osetska O. 8-hydroxyquinolines in metallosupramolecular chemistry. Coord Chem Rev. 2008;252(8-9):812-24.

3. Al-Busafi SN, Suliman FEO, Al-Alawi ZR. 8-Hydroxyquinoline and its derivatives: synthesis and applications, research and reviews. J Chem. 2014;3(1):1-14.

4. Rubbo SD, Albert A, Gibson MI. The influence of chemical constitution on antibacterial activity. V. The antibacterial action of 8-hydroxyquinoline (oxine). Br J Exp Pathol. 1950;31(3):425- 41.

5. Sahoo J, Paidesetty SK. Study of antimicrobial, analgesic wound healing and antioxidant activities of some newly synthesized oxychinolin derivatives and their characterization. Beni-suef Univ J Basic App Sci. 2015;4(3):232-45.

6. Vashi RT, Shelat CD. Transition metal complexation studies on heterocyclic ligands. Asian J Chem. 2010;22(3):1745-50.

7. Short BR, Vargas MA, Thomas JC, O'Hanlon S, Enright MC. In vitro activity of a novel compound, the metal ion chelating agent $A Q+$, against clinical isolates of Staphylococcus aureus. J Antimicrob Chemother. 2006;57(1):1049.

8. Moness E, Christiansen WG. Study of germicidal and antiseptic activities of some derivatives of 8-hydroxy quinoline. J Am Pharm Asso. 1934; 23(3): 228-32.

9. Kassem EM, El-Sawy ER, Abd-Alla HI, Manddour AH, Abdel-Mogeed D, El-Safty MM. Synthesis, antimicrobial, and antiviral activities of some new 5-sulphonamido-8- hydroxyquinoline derivatives. Arch Pharm Res. 2012;35(6):955-64.

10. Abdel-Moty SG, Abdel-Rahman MHHA, Elsherief Kafafy AHN. Synthesis of some quinoline thiosemicarbazone derivatives of potential antimicrobial activity. Bull Pharm Sci Assiut Univ. 2005;28:79-93.

11. Sau HC, Chung HC, Shun WC, Santon HLK, Dessy C, Miriam YTT Polly HML, Alfred KYL, Albert SCC, Kim HL, Johnny COT. Synthesis of 8-hydroxyquinoline derivatives as novel antitumor agents. ACS Med Chem Lett. 2013;4(2):170-4.

12. Mostafa AH, Abdel HNK, Samia GAM, Ola Mohammad AG. Synthesis and biological activities of new substituted thiazoline-quinoline derivatives. Acta Pharm. 2009;59(4):365-82.

13. Anuradha RC, Bhanudas SK, Swati CJ, Pradeep DO, Vasant VC, Suresh US, et al. Synthesis and evaluation of analgesic, anti-asthmatic activity of (E)1-(8-hydroxyquinolin-7-yl)-3-phenylprop-2-en-1ones. Arab J Chem. 2014; http://dx.doi.org/10.1016/j.arabjc.2014.10.046.

14. Veda P, Supaluk P, Somsak R, Virapong P. 8-Hydroxyquinolines: a review of their metal chelating properties and medicinal applications. Drug Design Dev Thera. 2013;7:1157-78.

15. Joseph J, Nagashri K, Ayisha BRG. Synthesis, characterization and antimicrobial activities of copper complexes derived from 4-aminoantipyrine derivatives. J Saudi Chem Soc. 2013;17(3):285-94.

16. Nejati K, Rezvani Z, Seyedahmadian M. The synthesis, characterization, thermal and optical properties of copper, nickel, and vanadyl complexes derived from azo dyes. Dyes Pigment. 2009;83(3):304-11.

17. Abdallah SM. Metal complexes of azo compounds derived from 4-acetamidophenol and substituted aniline. Arabian J Chem. 2012;5(2):2516.

18. Browing $\mathrm{CH}$, Cohen JB, Ellingworth S, Gulbransen R. The antiseptic properties of the amino derivatives of styryl and anil quinoline. J Stor. 1926;100(703):293-325

19. Khalid A, Arshad M, Crowley DE. Accelerated decolorization of structurally different azo dyes by newly isolated bacterial strains. Appl Microbiol Biotech. 2008;78(2):361-9.

20. Sahoo J, Paidesetty SK. Antimicrobial activity of novel synthesized coumarin based transitional metal complexes. J Taibah Univ Med Sci. 2016; htpp:// dx.doi.org/10.1016/j.jtumed.2016.10.004.

21. Sahoo J, Sahoo S, Paidesetty SK. Biological evaluation of novel a-heteroaryl/ arylazo 2-naphthol analogs and the transitional metal complexes derived from 4-((2-hydroxynaphthalen-1-yl) diazenyl)-1, 5-dimethyl-2-phenyl-1hpyrazol-3(2h)-one. Ind Drugs. 2016;53(7):15-24.

22. Sahoo J, Parween G, Sahoo S, Mekap SK, Sahoo S, Paidesetty SK. Synthesis, spectral characterization, in silico and in vitro antimicrobial 
investigations of some Schiff base metal complexes derived from azo salicylaldehyde analogues. Ind J Chem. 2016;55B:1267-76.

23. Garg HG, Praksh C. Preparation of 4-arylazo-3,5-disubstituted-(2H)-1,2,6thiadiazine 1,1-dioxides. J Med Chem. 1972;15(4):435-6.

24. Child RG, Wilkinson RG, Tomcu-Fucik A. Effect of substrate orientation of the adhesion of polymer joints. Chem Abstr. 1977;87:6031.

25. Thoraya AF, Abdallah ZA. Synthesis, azo- hydrazone tautomerism and antitumor screening of $\mathrm{N}$-(3-ethoxycarbonyl-4,5,6,7-tetrahydro-benzo[b] thien-2-yl)-2-arylhydrazono-3-oxobuta-namide derivatives. ARKIVOC. 2088;17:295-305.

26. Badea M, Olar R, Cristurean E, Marinescu D, Emandi A, Budrugeac P, Segal E. Thermal stability study of some azoderivatives and their complexes, Part 2. New azo-derivative pigments and their Cu (II) complexes. J Therm Anal Calor. 2004;77(3):815-24.

27. Khedr AM, El-Bindary AA, Abd El-Gawad AM. Stereochemistry of new nitrogen-containing heterocyclic compounds xiv. potentiometric and thermodynamic studies of 5-(phenylazo)-8-hydroxyquinolines and their metal complexes. Chem Pap. 2005;59(5):336-42.

28. Sahoo J, Paidesetty SK. Biological evaluation and spectral characterization of 4-hydroxy coumarin analogues. J Taibah Univ Med Sci. 2015;10:306-19.

29. Sahoo J, Paidesetty SK. Antimicrobial, analgesic, antioxidant and in silico study of synthesized salicylic acid congeners and their structural interpretation. Egyptian J Basic App Sci. 2015;2(4):268-80.

30. Amolegbe SA, Adewuyi S, Akinremi CA, Adediji JF, Lawal A, Atayese AO, et al. Iron(III) and copper(II) complexes bearing 8-quinolinol with amino-acids mixed ligands: Synthesis, characterization and antibacterial investigation. Arabian J Chem. 2015;8(5):742-7.

31. Sheikh J, Juneja H, Ingle V, Ali P, Hadda TB. Synthesis and in vitro biology of $\mathrm{Co}(\mathrm{II}), \mathrm{Ni}(\mathrm{II}), \mathrm{Cu}(\mathrm{II})$ and $\mathrm{Zinc}(\mathrm{II})$ complexes of functionalized betadiketone bearing energy buried potential antibacterial and antiviral 0,O pharmacophore sites. J Saudi Chem Soc. 2013;17(3):269-76.

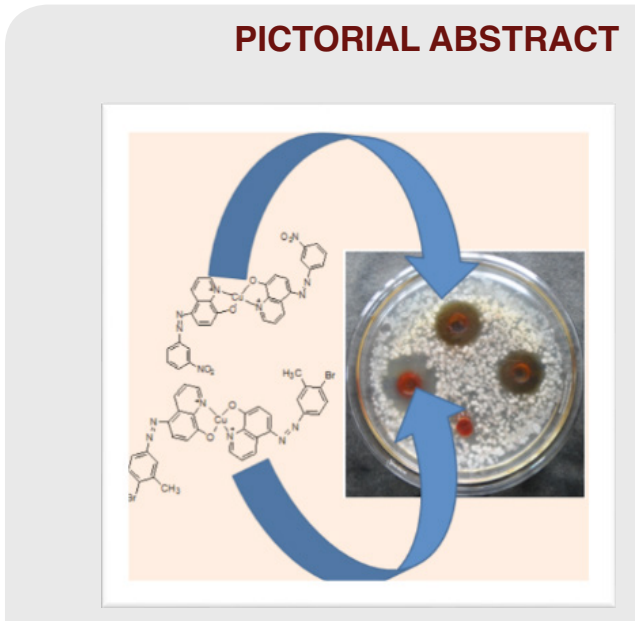

About Authors

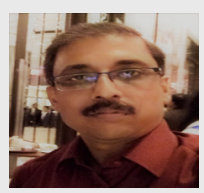

Dr. Jyotirmaya Sahoo is presently working as a faculty in Pharmacy at the Department of Pharmaceutics, Sri Jayadev College of Pharmaceutical Sciences, Bhubaneswar, Odisha (India). Dr. Sahoo is engaged in teaching and research since last seventeen years. He keeps his research interest in the development of synthetic hybrid molecules and to investigate their various biological activities. He also worked as a potential reviewer for various national and international journals. Dr. Sahoo is a life member of Association of Pharmaceutical Teachers of India, Indian Pharmaceutical Association, Indian Hospital Pharmacists Association, Orissa Chemical Society and Inpharm Association. He has a good number of research publications in various journals of national and international repute.

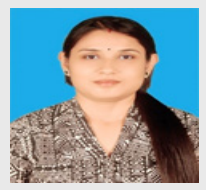

Ms. Priyambada Kshiroda Nandini Sarangi is presently working as Assistant Professor in Pharmaceutical Chemistry at Sri Jayadev College of Pharmaceutical Sciences, Bhubaneswar, Odisha (India). She is pursuing her Ph. D at Annamalai University. Ms. Sarangi is a member of Association of Pharmaceutical Teachers of India. She keeps her interest in the development of synthetic molecules as cytotoxic agents.

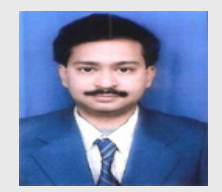

Dr. Sudhir Kumar Paidesetty is working as Associate Professor, Faculty of Pharmacy, School of Pharmaceutical sciences, Siksha 'O' Anusandhan University, Bhubaneswar, Odisha (India). He has kept his research interest in in silico investigation and biological evaluation of novel synthesized heterocyclic molecules. Dr. Kumar is a life member of Association of Pharmaceutical Teachers of India. He has published a number of publications in different journals and books in national and international repute.

Cite this article: Jyotirmaya S, Nandini SPK, Kumar PS. In vitro Antimicrobial Investigations of Newly Synthesized Transitional Bivalent Metal Complexes Derived from 8-Hydroxyquinoline. Indian J of Pharmaceutical Education and Research. 2017;51(3):480-9. 